\section{REVASCULARIZATION OF THE CIRCUMFLEX ARTERY WITH THE PEDICLED RIGHT INTERNAL THORACIC ARTERY: CLINICAL FUNCTIONAL AND ANGIOGRAPHIC MIDTERM RESULTS}

Retroaortic crossing of the pedicled right internal thoracic artery for revascularization of the circumflex artery used in combination with a pedicled left internal thoracic artery anastomosed to the left anterior descending artery and its branches is an attractive technique to achieve an extensive arterial revascularization of the left ventricle. However, there is a suspicion that pulling the right internal thoracic artery through the transverse sinus could compromise its blood flow capacity and patency. Between January 1990 and July 1994 this technique was applied in 256 patients (202 men, 54 women; average age 62 years, range 31 to 80 years). Sixty-one patients had two-vessel disease and 195 had three-vessel disease. Seventeen patients were undergoing a reoperation. Twenty-two had a left ventricular ejection fraction of $40 \%$ or less. Thirty had diabetes. Twentyeight had morbid obesity. The right internal thoracic artery was directed to the circumflex artery (259 anastomoses) through the transverse sinus and the left internal thoracic artery was anastomosed to the left anterior descending artery and its branches ( 375 anastomoses) in all patients. The 195 patients with three-vessel disease received additional coronary artery bypass grafts to the right coronary artery ( 93 saphenous vein grafts, 89 free inferior epigastric artery grafts, 12 pedicled right gastroepiploic artery grafts). In total, the 256 patients received 833 distal anastomoses (average 3.2, maximum 5 per patient) and 634 distal anastomoses were internal thoracic artery anastomoses (average 2.4 , maximum 4 per patient). Three patients died early and eight had a nonfatal myocardial infarction. Seven patients needed postoperative intraaortic balloon pump support. Six patients underwent early reoperation because of excessive bleeding. Sternal dehiscence occurred in four patients. One of these four patients died of the complication 10 months after the operation. No patient was lost to follow-up (average 33 months). During follow-up, two sudden deaths and six noncardiac deaths occurred. Two patients had a nonfatal myocardial infarction and 12 had recurrence of angina. There were no late reoperations. One patient underwent a successful percutaneous balloon angioplasty of a native left anterior descending artery. Seventy-four patients, enrolled in prospective angiographic studies, underwent a postoperative recatheterization (average 13.2 months, range 6 to 58 months). Seventy-three of the 74 right

Michel Buche, $\mathrm{MD}^{\mathrm{a}}$ (by invitation), Erwin Schroeder, $\mathrm{MD}^{\mathrm{b}}$ (by invitation), Patrick Chenu, $\mathrm{MD}^{\mathrm{b}}$ (by invitation), Olivier Gurne, $\mathrm{MD}^{\mathrm{b}}$ (by invitation), Bauduin Marchandise, $\mathrm{MD}^{\mathrm{b}}$ (by invitation), Giulio Pompilio, $\mathrm{MD}^{\mathrm{a}}$ (by invitation), Philippe Eucher, $\mathrm{MD}^{\mathrm{a}}$ (by invitation), Yves Louagie, $\mathrm{MD}^{\mathrm{a}}$ (by invitation), Robert Dion, $\mathrm{MD}^{\mathrm{a}}$ (by invitation), and Jean-Claude Schoevaerdts, MD $^{\mathrm{a}}$ (by invitation), Yvoir, Belgium Sponsored by Albert Starr, MD, Portland, Ore.
From the Departments of Cardiovascular and Thoracic Surgery ${ }^{a}$ and Cardiology, ${ }^{b}$ Catholic University of Louvain, Cliniques Universitaires UCL de Mont-Godinne, Yvoir, Belgium.

Read at the Seventy-fifth Annual Meeting of The American Association for Thoracic Surgery, Boston, Mass., April 23-26, 1995.

\footnotetext{
Address for reprints: Michel Buche, MD, Cliniques Universitaires UCL de Mont-Godinne, Service de Chirurgie Cardiovasculaire et Thoracique, B-5530 Yvoir, Belgium.

J THORAC CARdiovaSC Surg 1995;110:1338-43

Copyright (C) 1995 by Mosby-Year Book, Inc.

$0022-5223 / 95 \$ 5.00+0 \quad \mathbf{1 2 / 6 / 6 7 7 4 0}$
} 
internal thoracic artery grafts were patent. In comparison, 74 of 74 of the left internal thoracic artery grafts (106/107 anastomoses) were patent. Maximal stress thallium-201 scintigraphy results, obtained in 25 of those patients, did not reveal ischemia in the area of the circumflex artery. Extensive arterial revascularization of the left ventricle by means of both pedicled internal thoracic arteries can be done with acceptable mortality and morbidity. The midterm patency rate of the pedicled right internal thoracic artery when passed through the transverse sinus for bypassing the circumflex artery is excellent and does not differ from the patency rate of the left internal thoracic artery anastomosed to the left anterior descending artery. (J THORAC CARDIOvaSC SuRg 1995;110:1338-43)

$T^{\mathrm{h}}$ he left internal thoracic artery (LITA) used as a pedicled conduit for grafting the left anterior descending (LAD) artery provides a better patency rate and improves both the length and quality of survival in comparison with results with saphenous vein grafts. ${ }^{1,2}$ The desire to enhance these results has led surgeons to consider the other internal thoracic artery for additional arterial myocardial revascularization and to develop surgical techniques to extend its versatility. Retroaortic crossing of the right internal thoracic artery (RITA) for grafting the circumflex artery is one of these techniques. ${ }^{3}$ However, there is a suspicion that pulling the RITA through the transverse sinus could possibly compromise both its patency rate and its blood flow capacity. ${ }^{4,5}$ Here we present our experience with the use of this technique in 256 consecutive patients.

\section{Material and methods}

Between January 1990 and July 1994, 256 consecutive patients underwent grafting of the circumflex artery with a pedicled RITA, which was passed through the transverse sinus. These patients comprised 202 men and 54 women. The average age was 62 years (range 31 to 80 years). Thirty patients had diabetes and 28 had morbid obesity ( 1.5 times the patient's ideal weight). Eighty-four patients had a history of previous myocardial infarction; 17 less than 4 weeks before the operation. Twenty had had previous percutaneous transluminal coronary angioplasty and 17 had had previous coronary artery bypass grafting (CABG). One hundred seven patients were in Canadian Cardiovascular Society class IV, 100 in class III, and 49 in class II. Sixty-one patients had two-vessel disease and 195 had three-vessel disease; 67 had a stenosis of the left main coronary artery as well. The average left ventricular ejection function was $58 \%$ (range $28 \%$ to $80 \%$ ); 22 patients had a left ventricular ejection function less than $40 \%$. The other clinical characteristics and risk factors ${ }^{6}$ of these 256 patients are listed in Table I.

The technique under study was used in combination with "standard" grafting of the LAD (and if needed, its diagonal branches) with a pedicled LITA in all 256 patients (375 anastomoses). All these patients were operated on by the same surgeon (M. B.); they represent $80 \%$ of the patients having bilateral ITA grafting and $52 \%$ of the patients having bypass grafting of the circumflex arterial system by this surgeon during the same period. This illustrates our effort to apply this technique as liberally as possible. The main criteria used to select these patients were that they had a significant stenosis of a well-developed marginal branch of the circumflex artery and that the myocardium depending on this artery was viable. On the contrary diffuse and distal disease of the circumflex arterial system and a previous myocardial infarction involving the lateral wall of the left ventricle were the main contraindications to use of the technique. Risk factors such as diabetes, obesity, female gender, stenosis of the left main coronary artery of $70 \%$ or greater, or unstable angina by themselves were never sufficient to contraindicate the procedure in young patients ( $\leq 65$ years) or patients undergoing reoperation.

Operative technique. The technique used to take down the RITA is similar to the one used to take down the LITA. The RITA is mobilized with its adjacent veins, the surrounding fat or muscular tissues, and the endothoracic fascia. This pedicle is about $2 \mathrm{~cm}$ wide. The RITA is extensively dissected from its distal bifurcation in the rectus muscle up to the level of the subclavian vein. The RITA by its subclavian origin is freed from its pleural and thymic attachments and if necessary the confluence between the right internal thoracic vein and the azygos vein is divided to gain a maximum of length. ${ }^{7}$ Care is taken during this dissection not to injure the phrenic nerve. After dissection the RITA is forcefully sprayed with a solution of papaverine $(40 \mathrm{mg} / 100 \mathrm{ml})$ and wrapped with gauze patches soaked in the same solution. The RITA is divided after cannulation. The amount of RITA flow is never precisely measured and we only check the force of its free bleeding.

The operation is done with the use of systemic moderate hypothermia and cold potassium antegrade and retrograde cardioplegia. The pericardium anterior to the superior vena cava is cut down transversely and the RITA is passed behind the ascending aorta and the pulmonary artery. ${ }^{3}$ The pleural strip that covers the ventral side of the pedicle is used as a guide to avoid any twisting of the RITA. The pedicle is considered adequately positioned in the transverse sinus only when the free bleeding from the RITA remains brisk. Then the RITA is shortened to 
Table I. Clinical characteristics of 256 patients

$\begin{array}{lc}\text { Age (yr) } & 62(31-80) \\ \text { Sex ratio (M/F) } & 202 / 54 \\ \text { Angina CCS class } & \\ \quad \text { IV } & 107 \\ \text { III } & 100 \\ \text { II } & 49 \\ \text { Previous myocardial infarction } & 84 \\ \text { Reoperation } & 17 \\ \text { Previous PTCA } & 20 \\ \text { Diabetes mellitus } & 30 \\ \text { Morbid obesity } & 28 \\ \text { Hypertension } & 81 \\ \text { Hyperlipidemia } & 179 \\ \text { Smoking } & 98 \\ \text { Multilevel vascular disease } & 37\end{array}$

$M$, Male; $F$, female; CCS, Canadian Cardiovascular Society; PTCA, percutaneous transluminal coronary angioplasty.

match as adequately as possible the marginal branch of the circumflex artery that is to be bypassed. The left ventricle is lifted and rotated to the right to expose its lateral wall. Sewing the RITA to the circumflex artery in this position is easier than when the heart is not rotated but, on the other hand, requires additional length of the RITA. The pedicle may sometimes be tight during this part of the operation. However, the release of the heart after completion of the anastomoses always restores adequate length and looseness to the RITA.

The circumflex artery arteriotomy is about $5 \mathrm{~mm}$ in length. The anastomosis is done by the "parachute" technique with an 8-0 polypropylene continuous suture. ${ }^{8}$ After completion of the anastomosis the suture line and the pedicle are carefully inspected for bleeding and the pedicle is attached to the epicardium with a few stitches.

A total of 248 RITAs were used as single grafts and 3 were used for sequential grafting of two different marginal branches. Five others, after a side-to-side anastomosis to one marginal artery, were extended with a free inferior epigastric artery (IEA) graft directed to the distal branches of the right coronary artery. ${ }^{9}$ Three patients received additional saphenous vein grafts ( 5 anastomoses) to complete the revascularization of the circumflex artery. The 195 patients with three-vessel disease underwent complementary grafting of the right coronary artery system with 93 saphenous vein grafts, 89 free IEA grafts, and 12 pedicled right gastroepiploic artery grafts. The 256 patients received a total of 833 distal anastomoses (3.2 per patient, maximum 5). Of these anastomoses 634 were constructed with pedicled ITA grafts ( 2.4 per patient, maximum 4 ). Fourteen patients underwent concomitant procedures including 2 aortic valve replacements, 10 carotid endarterectomies, and 3 infrarenal aortic aneurysmectomies.

\section{Results}

Operative results. The hospital mortality rate was $1.2 \%$ ( 3 patients). One patient died of an acute tamponade 12 hours after operation. The two others died of low cardiac output after several days of in- traaortic balloon pump support. Five other patients required postoperative intraaortic balloon pump counterpulsation. The reason for use of the intraaortic balloon pump was a transmural perioperative myocardial infarction in three of these patients. In total, eight patients $(3.1 \%)$ had a perioperative nonfatal myocardial infarction (defined by either new $Q$ waves on postoperative electrocardiograms or a postoperative elevation of creatine kinase MB levels $\geq 10 \%$ of the total creatine kinase release). Six patients (2.3\%) required early reexploration because of excessive postoperative bleeding. In only one patient the bleeding came from a collateral branch of the RITA hidden in the transverse sinus. The pedicled RITA had to be converted into a free ITA graft to control the bleeding in this patient.

A sternal dehiscence occurred in four patients $(1.6 \%)$. One of these patients has diabetes. All four patients underwent immediate rewiring of the sternum over irrigation catheters. They received broadspectrum intravenous antibiotics for 6 weeks. The sternum healed definitively in three of them. The wound remained infected in a fourth patient who had a history of radiotherapy because of breast cancer. She underwent further debridement of the sternum and had coverage of the sternal wound with an omental flap. However, the infection could not be eradicated. Her course was complicated by a severe hemorrhage from the ascending aorta. This patient died of the complication 10 months after operation.

Late results. Complete follow-up of all patients was obtained by means of mailed questionnaires or telephone conversations with the general practitioners. The follow-up period averaged 33 months.

The late mortality rate was $2.7 \%$ ( 7 patients). Two patients died suddenly at home 3 months and 10 months after the operation, respectively. Their early postoperative course had been uneventful. Five other patients died of noncardiac causes (4 malignant diseases and 1 stroke) from 3 to 18 months after the operation.

Two patients had a nonfatal myocardial infarction 12 and 18 months after the operation, respectively. A routine angiogram obtained 6 months after operation in one of these two patients proved the RITA and all other grafts patent. A second angiogram, obtained on the occasion of the myocardial infarction, confirmed all grafts and anastomoses were still patent and functional. Twelve patients $(4.7 \%)$ had recurrence of exertional angina from 3 to 12 months after the operation. Five of these underwent post- 
operative recatheterization. None had occlusion of the RITA. Occlusion of a distal anastomosis of a sequential LITA occurred in one patient. This patient underwent successful percutaneous transluminal coronary angioplasty of the LAD.

Angiographic results. One hundred thirteen patients were enrolled in prospective angiographic studies (IEA, gastroepiploic artery, CABRI* trials). Of these, $74(65 \%)$ consented to undergo a postoperative angiographic restudy from 6 to 58 months (average 13.2 months) after the operation. Seventythree RITA grafts $(98 \%)$ were shown to be well patent and functional. One RITA graft was occluded. In comparison, all 74 LITA grafts were patent. Only 1 of the 107 LITA anastomoses was occluded (Table II).

Functional results. Twenty-five patients, in whom the RITA was angiographically patent, underwent maximal stress thallium-201 scintigraphy at the time of the angiographic restudy. None of those 25 patients showed any residual ischemia in the area of the circumflex artery.

\section{Discussion}

The incitement to use the ITA for CABG essentially began in the early 1980s when it was shown that both early and late patency rates of pedicled ITA grafts were higher than those of saphenous vein grafts. It also became clear that patients who received a pedicled LITA to the LAD had not only a higher late survival rate but also fewer cardiac events than those who received only saphenous vein grafts. ${ }^{1,2}$ Because a single ITA grafted to the LAD can improve the results of $C A B G$, we may expect even better results with use of the second ITA for bypassing the other major branches of the left coronary artery system.

This goal can be achieved by grafting the LAD with the pedicled RITA and the circumflex artery with the pedicled LITA. ${ }^{5}$ However, with this technique, the RITA is only just long enough to reach the proximal or middle third of the LAD and therefore cannot generally be used for sequential grafting of the LAD area. ${ }^{8}$ Another objection to this technique is that the RITA, by crossing the midline in front of the ascending aorta or the right ventricle, is at risk to be injured if a late reoperation through a median sternotomy is necessary. This risk can be easily prevented by passing the pedicled RITA

\footnotetext{
*Coronary Angioplasty Versus Bypass Revascularization Investigation.
}

Table II. Patency of pedicled RIMA anastomosed to circumflex artery via transverse sinus compared with patency of pedicled LIMA anastomosed to LAD

\begin{tabular}{lc}
\hline & Patency at \\
& 13.2 mo $(6-58 \mathrm{mo})$ \\
\hline RIMA grafts & $73 / 74$ \\
LIMA grafts & $74 / 74$ \\
LIMA anastomoses & $106 / 107$ \\
\hline
\end{tabular}

through the transverse sinus for grafting the circumflex arterial system, and the pedicled LITA can be used in a "standard" way for grafting the whole LAD system.

This technique was first described by Puig and associates $^{3}$ in 1984 . At that time its use was reported in 56 patients. Seventeen of these underwent postoperative coronary angiography. All the RITAs were patent and functional. The results reported by Rankin and associates ${ }^{4} 1$ year later were more disappointing. This group restudied 20 RITAs anastomosed to the circumflex artery marginal arteries via the transverse sinus. Two were occluded, 3 showed slow flow, and only $15(75 \%)$ were patent and functional. In comparison, the patency rate of the pedicled RITA anastomosed to the LAD was $100 \%(10 / 10)$ and the patency rate of the pedicled LITA anastomosed to the circumflex arterial system was also $100 \%(10 / 10)$. Consequently Rankin and associates ${ }^{4}$ decided to discontinue this technique in favor of others such as free ITA grafting techniques.

Our own experience does not support the suspicions of that group about the reliability of the procedure. In our study, 74 patients underwent angiographic restudy from 6 to 58 months after operation. The patency rate of the pedicled RITA directed to the circumflex arterial system through the transverse sinus established on this basis was excellent $(98 \%)$ and does not differ from the rate for the pedicled LITA anastomosed to the LAD. The same conclusions were reached by Dion and associates $^{10}$ in an even larger cohort of patients. Its efficacy in providing sufficient blood flow to the lateral wall of the left ventricle is also clearly shown by the fact that none of the 25 patients (with a well-patent RITA) who underwent maximal stress thallium-201 scintigraphy had any residual ischemia in the circumflex arterial area. In addition, this technique does not seem to increase the perioperative mortality or cardiac morbidity. In our study, the in-hospital mortality rate was $1.2 \%$ and the preva- 
lence of perioperative nonfatal myocardial infarction was $3 \%$. We believe that these results are similar to those currently obtained in common CABG. ${ }^{11}$

There is no doubt that the use of bilateral ITAs has increased the prevalence of sternal complications observed in our study (1.5\%). A similar prevalence of sternal wound complication has been reported by others dealing with bilateral ITA grafting. ${ }^{10,12}$ However, this risk, even if bothersome, is not so crucial that the technique has to be avoided.

Another specific reason not to use this technique has been that it would be difficult or even impossible to control any postoperative bleeding from the circumflex arterial anastomosis or from the pedicle of the RITA in its course behind the ascending aorta or the pulmonary artery without the help of cardiopulmonary bypass. ${ }^{13}$ In our study six patients needed early mediastinal reexploration because of excessive postoperative bleeding within the first 24 postoperative hours and only one of them bled from the transverse sinus. In that case the RITA was simply detached from its subclavian origin and pulled out of the transverse sinus from the right to the left. The collateral branches of the RITA causing the bleeding were easily clipped. After this the RITA was proximally implanted onto the ascending aorta via the hood of a saphenous vein graft directed to the right coronary artery. The subsequent course of this patient was uneventful.

Only the length of the pedicled RITA, in fact, can limit the feasibility of this technique when the extreme distal segment of a circumflex artery has to be reached and when sequential grafting of the circumflex arterial area is necessary, particularly in the presence of left ventricular dilation. Additional length of about $2 \mathrm{~cm}$ can be easily gained by dividing the right internal thoracic vein proximally or by straightening the tortuous course of the RITA by means of either a longitudinal incision of the ventral aspect of the pedicle up to the subclavian artery ${ }^{10}$ or staged transversal incisions. ${ }^{7}$ Despite these artifices, it remains difficult to routinely bypass more than one marginal branch of the circumflex arterial system with a pedicled RITA without taking the risk of compromising both its patency and function. Many surgeons would then advocate the use of the RITA as a free graft. However, the patency of free ITA grafts is usually much lower than that of pedicled ITA grafts, ${ }^{10,14}$ and therefore whenever possible we prefer to direct the pedicled RITA to the most important marginal branch and to complete the revascularization of the circumflex artery system by means of additional saphenous vein grafts, free IEA grafts, or pedicled gastroepiploic artery grafts.

Tector and associates ${ }^{15}$ have recently reported a "conduit to conduit" technique that may challenge our option. These investigators constructed Yshaped ITA grafts by anastomosing free RITAs on proximal pedicled LITAs in a T-shaped configuration. By that technique they were able to bring the patency rate of free RITAs up to $91 \%$. However, we believe that this technique is more demanding, carries the risk of jeopardizing both ITA grafts, and renders the entire left ventricular perfusion dependent on the sole LITA pedicle.

In conclusion, extensive arterial revascularization of the left ventricle by means of both pedicled ITAs can be achieved with acceptable mortality and morbidity. The midterm patency rate of the pedicled RITA passed through the transverse sinus for grafting the circumflex artery is excellent and does not differ from the patency rate of the pedicled LITA anastomosed to the LAD. We expect that the longterm patency will also be similar for both pedicled grafts. Event-free survival is expected to be improved by this technique.

\section{REFERENCES}

1. Grondin CM, Campeau L, Lesperance J, Enjalbert M, Bourassa MG. Comparison of late changes in internal mammary artery and saphenous vein grafts in two consecutive series of patients 10 years after operation. Circulation 1984;70(Suppl):I208-12.

2. Loop FD, Lytle BW, Cosgrove DM, et al. Influence of the internal mammary artery graft on 10-year survival and other cardiac events. N Engl J Med 1986;314:1-6.

3. Puig LB, Neto LF, Rati M, et al. A technique of anastomosis of the right internal mammary artery to the circumflex artery and its branches. Ann Thorac Surg 1984;38:533-4.

4. Rankin JS, Newman GE, Bashore TM, et al. Clinical and angiographic assessment of complex mammary artery bypass grafting. J THORAC CARdIOvasC SURG 1986;92:832-46.

5. Ramström J, Lund O, Cadavid E, Oxelbark S, Thuren JB, Henze AC. Right internal mammary artery for myocardial revascularization: early results and indications. Ann Thorac Surg 1993;55:1485-91.

6. Clark RE. Definitions of terms of the Society of Thoracic Surgeons national cardiac surgery database. Ann Thorac Surg 1994;58:271-3.

7. Cosgrove DM, Loop FD. Techniques to maximize mammary artery length. Ann Thorac Surg 1985;40: 78-9.

8. Dion R, Verhelst R, Rousseau M, et al. Sequential 
mammary grafting: clinical, functional and angiographic assessment 6 months postoperatively in 231 consecutive patients. $J$ Thorac Cardiovasc Surg 1989;98:80-9.

9. Buche M, Schroeder E, Devaux Ph, Louagie YAG, Schoevaerdts JC. Right internal mammary artery extended with an inferior epigastric artery for circumflex and right coronary bypass. Ann Thorac Surg 1992;54: 381-3.

10. Dion R, Etienne PY, Verhelst R, Khoury G, Rubay J, Bettendorff $\mathrm{Ph}$. Bilateral mammary grafting: clinical, functional and angiographic assessment in 400 consecutive patients. Eur J Cardiothorac Surg 1993;7:287-94.

11. Kirklin JW, Neftel DC, Blackstone EH, Pohost GM. Summary of a consensus concerning death and ischemic events after coronary artery bypass grafting. Circulation 1989;79(Suppl):I81-91.

12. Lytle BW, Cosgrove DM, Loop FD, Borsh J, Goormastic M, Taylor PC. Perioperative risk of bilateral internal mammary artery grafting: analysis of 500 cases from 1971 to 1984. Circulation 1986;74(Suppl): III37.

13. Quentin RS. Discussion of Dion R, Verhelst R, Rousseau $M$, et al. Sequential mammary grafting: clinical, functional and angiographic assessment 6 months postoperatively in 231 consecutive patients. $\mathrm{J}$ Thorac Cardiovasc Surg 1989;98:88.

14. Loop FD, Lytle BW, Cosgrove DM, Golding LAR, Taylor PC, Stewart RW. Free (aorta-coronary) internal mammary artery graft: late results. J THORAC Cardiovasc SurG 1986;92:827-31.

15. Tector AJ, Amundsen S, Schmahl TM, Kress DC, Peter M. Total revascularization with $\mathrm{T}$ grafts. Ann Thorac Surg 1994;57:33-9.

\section{Discussion}

Dr. Bruce W. Lytle (Cleveland, Ohio). There is much evidence that the two best bypass grafts available are the LITA and RITA. The bulk of the data applies to the LITA graft to the anterior descending coronary artery. Certainly many other issues about ITA grafting to other vessels are yet to be resolved.

The authors have directed their efforts at a specific question. A few years ago data were presented that appeared to show a risk of compression of the RITA if it was brought through the transverse sinus to the circumflex coronary artery. The authors have a series of 70 -odd recatheterizations that shows that if that does happen, it does not happen very often, and that is an important fact to understand. It is difficult, almost impossible, in the United States to study consecutive series of patients. This is not a consecutive series of restudies, but it is pretty good. It comprises a large number of patients, which is helpful.

My only question relates to reoperation in this setting. Have you reoperated on patients with this type of bypass graft that is patent, and how easy or difficult was it?

Dr. Buche. We have not yet had to reoperate on any of those patients, but we hope that it will be easier to reoperate on those patients with the RITA passing through the transverse sinus than to have to cope with the RITA passing just under the sternum.

Dr. Paulo Rodrigues DaSilva (Rio De Janeiro, Brazil). I agree with the authors' use of the ITA, but other grafts must be used as well.

We have been using a sequential $\mathrm{CABG}$ whereby the right marginal coronary artery bed is the runoff of the last sequential anastomosis. This surgical technique is based on the fact that the heart has two different total peripheral vascular resistances (TPVRs), one lower from the right ventricular wall and another ten times higher from the left ventricular wall. For this, in the proximal right coronary artery bypass the intravascular flow is very hard.

Applying this innovative surgical technique in $28 \mathrm{pa}-$ tients, 24 with saphenous vein grafts and four with the radial artery grafts, we found an intraluminal blood flow velocity $90 \%$ higher, a TPVR $80 \%$ lower, and an intraluminal graft blood pressure $25 \%$ lower than those found in classic aorta-coronary artery bypass grafts. Four of our patients were evaluated 3 to 4 years after the operation, and the anastomosis was patent in all.

Dr. Carpentier's therapeutic protocol for patients with radial artery $C A B G s$ recommends the use of calcium channel blockers, which decrease the ventricular wall TPVR and the platelet inhibitors somehow related to the decreasing of blood flow velocity. The proposed surgical technique physiologically gives the same hemodynamic support achieved by those medications.

On the basis of the higher intraluminal blood flow velocity, the lower intraluminal graft blood pressure, and the lower TPVR achieved, the proposed technique apparently increases the patency rate of the saphenous vein graft, will delay the atherosclerotic degeneration of the saphenous vein wall tissue, and will minimize the spastic episodes from arterial conduits like the radial artery. It is a new option to achieve total arterial graft myocardial revascularization. 